\title{
Experience Gained from Ecotoxicological Studies in the Seine River and Its Drainage Basin Over the Last Decade: Applicative Examples and Research Perspectives
}

\author{
M. Bonnard, I. Barjhoux, O. Dedourge-Geffard, A. Goutte, L. Oziol, \\ M. Palos-Ladeiro, and A. Geffard
}

\section{Contents}

1 Introduction

2 Value of In Vitro Bioassays for an Ex Situ Evaluation of Water Contamination: The Case of Endocrine Disruptors

2.1 In Vitro Endocrine Disruptor Bioassays in Water Contamination Monitoring ..... . 246

2.2 Comparison of In Vitro Bioassays to Chemical Analysis in Water Contamination

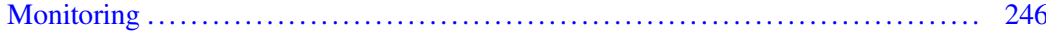

2.3 In Vitro Bioassays Applied to Sediment Matrix in Aquatic Environment Quality

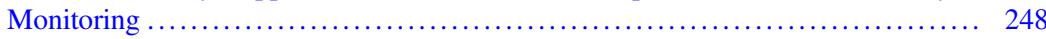

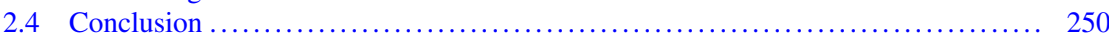

3 Biomarkers for the In Situ Biomonitoring of Water Contamination .................. 250

3.1 Presentation of Sentinel Species and Their Advantages in Ecotoxicological Studies 250

3.2 Monitoring of Oxidative Stress in Fish Models .......................... 252

3.3 Value of Digestive Activities as Biomarkers in Two Aquatic Invertebrates: Application to the Seine River Basin ............................. 253

3.4 Value of Haemocytes of Zebra Mussels for the Development of Immune

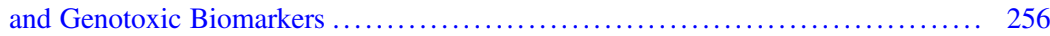

4 Combining Multidisciplinary Data for a Global Environmental Quality Diagnosis:

Development of an Integrated Approach ................................ 259

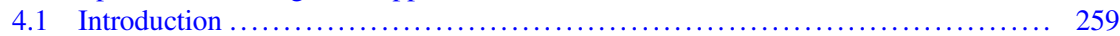

4.2 The WOE Methodology: Towards an Index of Ecological Disturbance ......... 260

The copyright year of the original version of this chapter was corrected from 2019 to 2020. A correction to this chapter can be found at https://doi.org/10.1007/698_2020_667

M. Bonnard ( $\bowtie)$, I. Barjhoux, O. Dedourge-Geffard, M. Palos-Ladeiro, and A. Geffard Université de Reims Champagne-Ardenne (URCA), UMR-I 02 SEBIO, Reims, France e-mail: marc.bonnard@univ-reims.fr

A. Goutte

PSL University, UMR 7619 METIS, SU/CNRS/EPHE, Paris, France

L. Oziol

Université Paris-Sud, CNRS, AgroParisTech, UMR 8079 ESE, Orsay, France 
4.3 Application of the Integrative WOE Approach to a 1-Year Case Study on the Seine

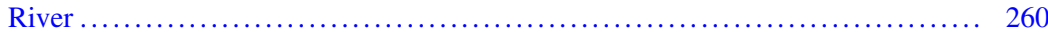

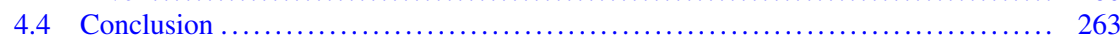

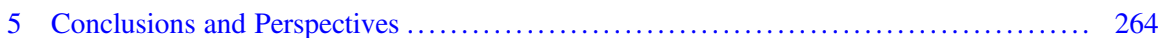

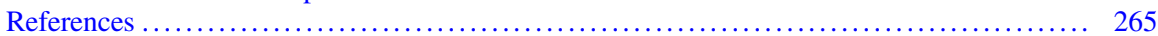

\begin{abstract}
The Seine River and its drainage basin are recognised as one of the most urbanised water systems in France. This chapter gathers typical applications of complementary ecotoxicological tools that were used in PIREN-Seine programmes for a decade to reflect the Seine River contamination as well as its biological repercussions on organisms. Ecotoxicological studies focused on both (1) specific bioassays and (2) (sub)-individual biological responses (i.e. biomarkers) measured in diverse taxa (i.e. crustaceans, mussels and fishes) representative of the trophic network. Experience gained from these studies made it possible to establish reference and threshold values for numerous biological endpoints. They now can be combined with chemical measurements within integrated models (i.e. the Weight of Evidence [WOE] approach) generating a global index of waterbody pollution. These biological endpoints today appear sufficiently relevant and mature to be proposed to water stakeholders as efficient tools to support environmental management strategies.
\end{abstract}

Keywords Bioassays, Biomarkers, Biomonitoring, eLTER, Freshwater ecotoxicology, PIREN-Seine, WOE approach, Zone Atelier Seine

\title{
1 Introduction
}

The Seine basin is subjected to multiple anthropogenic pressures including intensive agricultural activities and some heavy urbanisation and industrialisation within the Paris conurbation and its surrounding areas [1]. This wide variety of anthropogenic pressures affecting the Seine watershed makes this area an ideal area to study contemporary environmental issues. The short- and long-term repercussions of such diffuse and chronic pressure on ecosystem health remain difficult to evaluate, considering the complexity and the diversity of these exogenous inputs. The contamination level can be determined through chemical analysis as defined by the presence of substances that would not normally occur or at concentrations above the natural background. However, the pollution status assessment additionally integrates chemical bioavailability and the biological impacts of contaminants [2]. Consequently, integrated and multidisciplinary strategies are clearly recommended and even required by the European Water Framework Directive 2000/60/CE [3]. One of the main strengths of the PIREN-Seine programme is that it is based on a substantial interdisciplinary scientific network, whose partners work jointly contributing their own expertise to improve the understanding of the ecological and biogeochemical functioning of the whole Seine watershed, including human-induced modifications. 
Two main strategies have been used in the PIREN-Seine programme for a decade in order to characterise the ecotoxicological status of the Seine waterbodies. The first one has consisted in an ex situ strategy with the development of complementary bioassays performed on cell cultures and/or laboratory model organisms to investigate the (eco)toxicity of environmental samples. In particular, the study of the oestrogenic potential of water and sediment samples using specific in vitro bioassays is illustrated in this chapter (see Sect. 2). The second strategy consisted in in situ measurements of various biological responses, called biomarkers, to reflect the impacts on sentinel species. This approach is illustrated here with examples of studies conducted on (1) field populations for fish species, i.e. passive biomonitoring, and (2) transplanted organisms for aquatic invertebrates such as mussels and crustaceans, i.e. active biomonitoring (see Sect. 3). Most of these ecotoxicological studies investigated three pilot sites of the Seine River, upstream and downstream of the Paris agglomeration (i.e. Marnay, Bougival and Triel-sur-Seine) and, more episodically, sites on the Orge River, an important tributary of the Seine River. Experience gained from all these studies allowed establishing reference and threshold values for many biological endpoints. They now can be combined with chemical measurements within integrated models (i.e. the Weight of Evidence [WOE] approach; see Sect. 4) generating a global index of waterbody pollution.

\section{Value of In Vitro Bioassays for an Ex Situ Evaluation of Water Contamination: The Case of Endocrine Disruptors}

Among pollutants discharged into the environment, many belong to the family of endocrine disruptors (EDs), chemicals able to lead to endocrine disorders in both humans [4] and wildlife [5], even at trace levels. Polychlorinated biphenyls (PCBs), polybrominated diphenyl ethers (PBDEs) and phthalates are such chemicals, which have been quantified both in water and the roach Rutilus rutilus in the Seine basin [6]. The main ED disorders may affect the oestrogenic pathway of aquatic species and induce the 'feminisation' of male fishes in some cases [7]. However, aquatic contaminants may target other endocrine axes. Among the endocrine-disrupting effects affecting oestrogenic, androgenic or thyroid endpoints, the most pronounced effects of aquatic contamination were oestrogenicity, as brought to light by a European research programme [8]. In this context, in vitro bioassays applied for endocrine disruptors $[9,10]$ are a good compromise between in situ bioassays, which can be expensive and time- and animal-consuming, and hence not suitable as highthroughput screening tools, and chemical analyses, which are limited to a restricted number of quantified pollutants and do not allow one to consider their harmful effects in mixtures representative of an in situ exposure. In vitro bioassays can therefore be considered as intermediate sensitive and global screening tools for monitoring aquatic ED contamination, to assess its intrinsic dangerousness because they integrate interaction effects (additive, antagonistic or synergistic) between low doses of chemicals (cocktail effects). Such in vitro cellular bioassays were used for 
the monitoring of organic pollution by endocrine disruptors in European surface waters [8] and were also implemented in the PIREN-Seine programme for the evaluation of the Seine River quality. Only data of oestrogenic activities are presented, given their ubiquity and levels in both the water column and sediments.

\subsection{In Vitro Endocrine Disruptor Bioassays in Water Contamination Monitoring}

The oestrogenicity of the organic contamination of surface waters collected over nine campaigns between February and November 2010 at Marnay-sur-Seine, Bougival and Triel-sur-Seine was studied using the MELN reporter gene assay according to [11]. Regardless of the sampling location, surface waters showed significant oestrogenic-mimetic activities, on the order of $1 \mathrm{ng} \mathrm{E} 2-\mathrm{eq} / \mathrm{L}^{1}$ : median $\mathrm{EEQ}^{1}$ values of $0.27,0.40$ and $0.51 \mathrm{ng}$ E2-eq/L were measured for Marnay-surSeine, Bougival and Triel-sur-Seine, respectively [12]. Similar oestrogenic activity levels were reported under the PIREN-Seine programme for organic contamination of rivers sampled in the Orge catchment area near Paris during September 2007 [13]. Both mean and median EEQ values were the lowest for Marnay-sur-Seine and the highest for Triel-sur-Seine. The data tended to highlight an upstreamdownstream gradient of increasing oestrogenic activity in the Seine River: Marnay-sur-Seine $<$ Bougival $<$ Triel-sur-Seine, even if temporal variations due to hydrologic conditions may mask the increasing gradient when the results are averaged over the year. Indeed, the strongest mean oestrogenic activity was observed for Bougival water sampled in July [12], corresponding to the low-flow period. The same general pattern was shown for Triel-sur-Seine. In contrast, the lowest oestrogenic activities were detected in winter, highlighting a dilution of water contamination during high-flow periods. Overall, the cellular bioassay implemented made it possible to monitor the Seine River contamination by bioactive chemicals at the oestrogenic axis, in accordance with both seasonal and spatial expected distribution of pollution.

\subsection{Comparison of In Vitro Bioassays to Chemical Analysis in Water Contamination Monitoring}

The in vitro bioassays may be used alone or in combination with chemical analysis to monitor the aquatic contamination by endocrine disruptors. In the framework of the

\footnotetext{
${ }^{1}$ The transcriptional activities measured using in vitro ED bioassays are generally expressed as $17 \beta$-estradiol (E2) equivalent (eq) quantity (EEQ), in $\mathrm{ng}$ E2-eq/L of water or in $\mathrm{ng}$ E2-eq/g of sediment, by comparing them with the activity of the specific hormonal ligand E2.
} 
PIREN-Seine programme, several chemicals were analysed in water samples. Among them, the following oestrogens were especially analysed, the natural oestrogens, E2 or its isoform $\alpha$, oestrone (E1) and oestriol (E3) and the synthetic one, ethinylestradiol (EE2), and their contribution to the oestrogenic potential of the water column was studied. For this purpose, the oestrogenic potency of water samples collected between February and November 2010 in Marnay-sur-Seine, Bougival and Triel-sur-Seine was expressed in two ways: as biological EEQ in ng E2-eq/L derived from the bioassay approach and as chemical EEQ in ng E2-eq/L, corresponding to the sum of the relative biological potency to E2 of each oestrogen multiplied by their respective concentration in the dissolved phase of water samples [13]. Thus, the biological EEQs measured were compared to the chemical EEQ estimated according to E2 (isoforms $\alpha$ and $\beta$ ), E1, E3 and EE2 concentrations weighted by their respective oestrogenicity on MELN cells [12]. A good correlation was highlighted between chemical and biological EEQs on all the three Seine axis pilot sites, the correlation coefficient $\mathrm{R}$ values ranging from 0.84 for Marnay-surSeine to 0.99 for Bougival.

Other contaminants, known or suspected as endocrine disruptors, were monitored during these water-sampling campaigns: phthalates, alkylphenols, polycyclic aromatic hydrocarbons (PAHs), PCBs, PBDEs and bisphenol A [12]. Among these chemicals, only 4-nonylphenol and bisphenol A are proven endocrine disruptors, with reference toxicological values established regarding their ED effects $[14,15]$. For all water samples, the correlation between biological and chemical EEQs was much weaker for 4-nonylphenol $(R=0.57)$ and bisphenol A $(R=0.73)$ than for oestrogens $(R=0.96)$, with $\mathrm{E} 2$ as the largest contributor by far to the oestrogenicity of surface waters from the Seine River, followed by E1, in accordance with most studies reviewed by [16]. E3 and EE2 were not detected in the water samples collected in 2010, unlike in previous samples from the Orge catchment in 2007 [13]. Comparatively, bisphenol A and 4-nonylphenol contributed to a minor extent $(\sim 2 \%)$ to the ED potential of Seine River organic contamination. A safe oestrogenic equivalent value of $0.3 \mathrm{ng} \mathrm{E} 2-\mathrm{eq} / \mathrm{L}$, regarding steroid oestrogens, was based on the assumption that these chemicals are responsible for more than $90 \%$ of in vitro oestrogenicity of municipal wastewater treatment plant effluents [16]. The abovementioned results are in line with this consideration, and the proposed provisional trigger value was exceeded by mean EEQ values measured for water samples from downstream Seine River sites: Bougival (0.84 ng E2-eq/L) and Triel-sur-Seine (0.55 ng E2-eq/L). In the latter campaigns (2011-2012), the trigger value was exceeded only for water samples from Triel-sur-Seine, especially in June 2012, showing an EEQ of $2.1 \mathrm{ng}$ E2-eq/L. 


\subsection{In Vitro Bioassays Applied to Sediment Matrix in Aquatic Environment Quality Monitoring}

Since biological activity of dissolved phase samples may reflect only an intermittent contamination of surface waters, in vitro bioassays were also applied to sediment samples. Indeed, sediments act as a pollution storage tank concentrating many persistent or pseudo-persistent compounds for long periods (e.g. PAHs, PCBs, sex steroids, alkylphenols, plasticisers) as shown for French sediments [17-19]. In this context, the oestrogenic potential was simultaneously measured on sediment and water samples collected in the three pilot sites of the Seine axis during three sampling periods in 2011-2012, using the MELN bioassay [20]. The spatial and temporal oestrogenicity of sediment organic extracts are shown in Fig. 1a, b, respectively.

The oestrogenicity dose-response curves showed a clear upstream-downstream gradient for sediments collected during the low-flow period (June 2012) (Fig. 1a), with EEQ values ranging from 1.95, 0.867 to $0.0005 \mathrm{ng}$ E2-eq/g, for Triel, Bougival and Marnay, respectively. These EEQ levels were in accordance with those observed between small good-quality French rivers (Aisne, Vallon du Vivier and Lézarde Rivers with oestrogenicity at $0.20-0.83 \mathrm{ng}$ E2-eq/g sediment) and poor-quality rivers (Rhonelle and Réveillon, with oestrogenicity at 1.69 and $6.43 \mathrm{ng}$ E2-eq/g sediment, respectively) according to French water agencies [18]. Triel-sur-Seine sediments collected in the low-flow period showed a higher activity (EEQ, $1.95 \mathrm{ng}$ E2-eq/g in June 2012) than those sampled during other periods (EEQ, approximately $0.3 \mathrm{ng}$ E2-eq/g for September 2011 and December 2012) (Fig. 1b). These spatial and temporal variations in the oestrogenic potential of Seine River sediment were in accordance with those evidenced for water samples (Fig. 1). Furthermore, the sediments showed differences in oestrogenic activity in accordance with their contamination levels in various hydrophobic and persistent organic pollutants belonging to ED compound families (PAHs, PCBs, organochlorine pesticidesOCPs, PBDE) [20].

Contrary to the water column, today there are no trigger values for sediment oestrogenicity regarding the environmental risks for benthic organisms [21]. Over the two matrices studied, sediment appears, however, as the most suitable for highlighting the ubiquitous oestrogenicity of the aquatic contamination and the time-space variations of its biological activity. Compared to intermittently collected water samples, the sediment extracts are more concentrated (while being noncytotoxic in the MELN bioassay) and integrate long-term contaminations. As a result, the fold inductions of oestrogenic activity obtained with sediment extracts (from $\times 4$ to $\times 30$ in comparison to blank samples; Fig. 1) were greater than those obtained with dissolved phase extracts (from $\times 3$ to $\times 12$ ), ensuring quantifiable transcriptional activities in each sediment sample, contrary to water samples. 

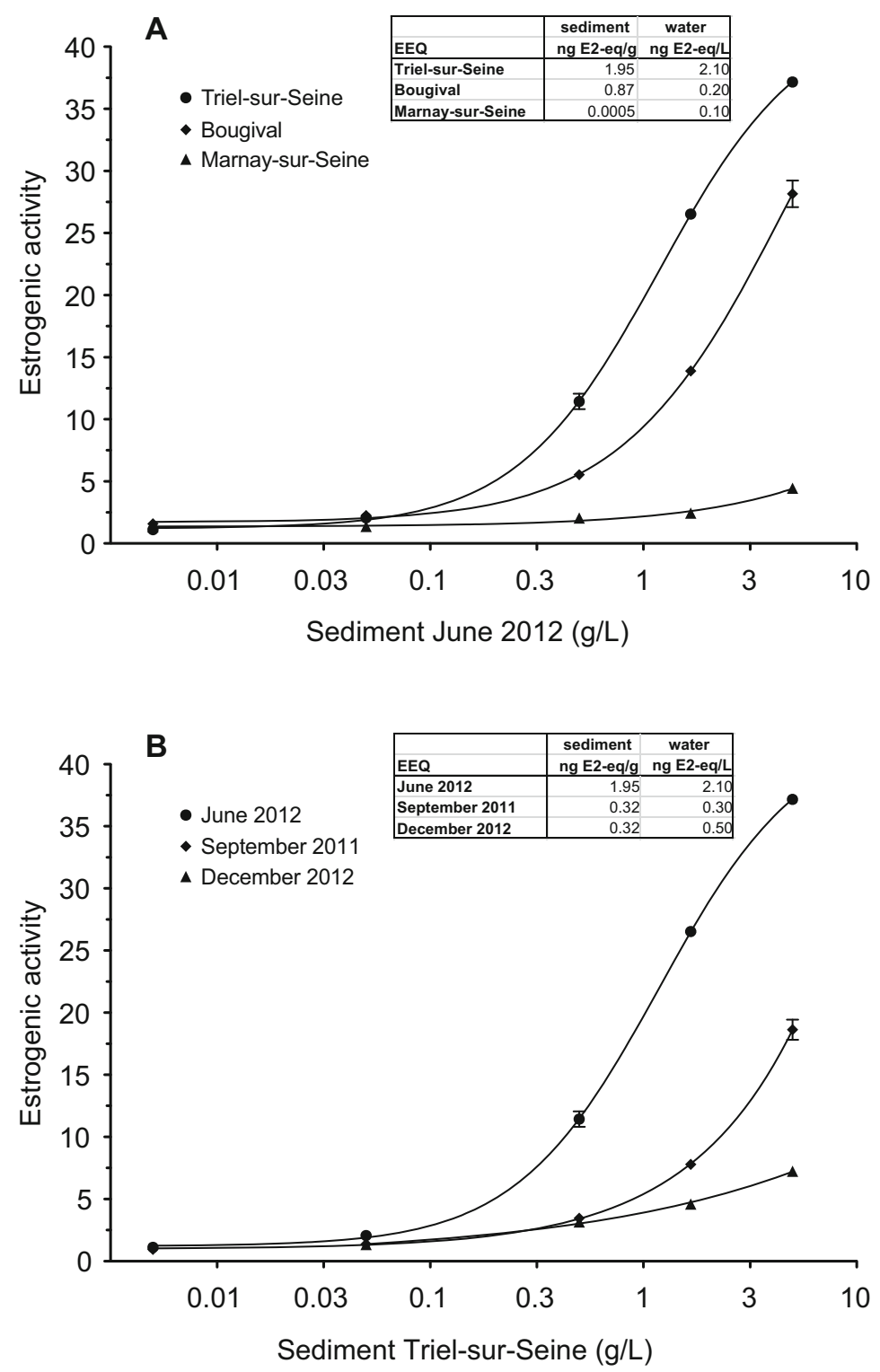

Fig. 1 Spatial (a, for June 2012 samples) and temporal (b, for Triel-sur-Seine samples) variation of the oestrogenic potential in sediments (in $\mathrm{g} / \mathrm{L}$ of culture medium in the MELN bioassay) collected from the Seine River in September 2011, June 2012 and December 2012 at Marnay-sur-Seine, Bougival and Triel-sur-Seine. Graph data correspond to mean \pm SEM of one experiment repeated three times. Insert data represent EEQ values in ng E2-eq/g and in ng E2-eq/L of the dissolved phase of water samples collected at the same time 


\subsection{Conclusion}

The quality of surface waters was monitored alongside the Seine River over 2010-2012 using in vitro bioassays of oestrogenicity applied on sediment and water matrix contamination. The results highlighted a contamination gradient by bioactive chemicals, increasing from upstream (Marnay-sur-Seine) to downstream (Bougival and Triel-sur-Seine). In addition, a lower oestrogenic potential of both water and sediment contamination was observed under high-flow conditions (winter) compared to low-flow periods (summer). The in vitro bioassay implemented revealed an acceptable quality of the Seine River upstream of Paris but a degraded quality downstream of Paris according to the provisional trigger values for endocrine disruptor contamination of the water column. These data are overall in accordance with those from other bioassays of ED or toxic potential measurements on sediment or water matrices collected in the same three pilot sites in the PIREN-Seine programme [20]: bioassays measuring thyroidicity (PC-DR-LUC cells), antiandrogenicity (MDA-kb2 cells), embryotoxicity/teratogenicity on fish (Medaka embryo-larval assay), cytotoxicity (Microtox ${ }^{\circledR}$ assay) and genotoxicity (SOS chromotest). In conclusion, in vitro bioassays stood out as being suitable tools to monitor the quality of the Seine River. In addition, sediment may be considered as a suitable matrix to monitor aquatic pollution using a bioassay-based approach, since it is able to concentrate bioactive aquatic pollutants of a wide range of polarities and especially to act as an integrative adsorbent matrix of the ongoing environmental contamination by anthropic chemicals.

\section{Biomarkers for the In Situ Biomonitoring of Water Contamination}

\subsection{Presentation of Sentinel Species and Their Advantages in Ecotoxicological Studies}

To highlight the water contamination status, it seems wise to develop indicators integrating the daily spatial and temporal variability of contaminant concentrations in surface waters. Besides direct in situ measurements, the integration of contamination in wild organisms could contribute further information on environmental hazard [22]. Moreover, since the exposure, biotransformation and effects pathways of contaminants may differ between vertebrates and invertebrates; biomarkers need to be studied in diverse taxa for an ecological relevance.

Biomonitoring of wild fish provides a spatially and temporally integrated view of pollutant exposure and ecotoxicological effects, because of their relatively high mobility, long life span (bioaccumulation over time [23]), high trophic levels (i.e. biomagnification [24]) and slow genetic adaptation due to a slow turn over [25]. The European chub (Squalius cephalus L.) is extensively used as a bioindicator 
species in field studies [26-28]. This fish species is common and widely distributed throughout Europe, in both clean and polluted freshwaters [29]. The abundance growth rate is stable in France, and feral chubs in the Seine River occur in satisfactory numbers to allow ecotoxicological field studies. Previous studies have highlighted the high sensitivity of chubs to pollutants, with high levels of DNA damage and high EROD (ethoxyresorufin-O-deethylase) activity [30-32] in polluted freshwaters.

Aquatic invertebrates such as filter feeders (bivalves) or detritivorous species (amphipods) are good sentinel species. Bivalves can concentrate and retain contaminants in their tissues for a long time, which represents a valuable integrative characteristic. Among continental bivalves, studies are mainly based on a model organism, the zebra mussel Dreissena polymorpha, which has proved its value [33]. D. polymorpha, originating from the Ponto-Caspian region, is characterised by its abundance and widespread distribution in European and North American rivers, great filtration capacities leading to high levels of xenobiotic accumulation and good tolerance to environmental stressors [33]. As regards amphipod crustaceans, the genus Gammarus plays a key role in food webs such as the common shredder, playing a major role in leaf-litter breakdown. The reduction in its feeding activity is directly correlated with the reduction in the processing of leaf litter [34]. Furthermore, in Gammarus spp., the ingestion of leaves leads to the assimilation of energy and the production of faecal pellets. Gammarids and their faeces are a food resource for many aquatic species. Since Gammarus fossarum is widespread in Central and Eastern Europe, this common species has been defined as a very good candidate to study the impact of chemical stressors.

In accordance with their sedentary lifestyle, individual responses of the invertebrates used as biomarkers may be correlated with the quality of the sampling site, thereby allowing for the development of early warning and sensitive diagnosis tools exhibiting high ecological relevance [35]. Biomarkers related to energy metabolism [36] and immune functions could be useful prognostic tools, bearing in mind the close relationships existing between the energy balance and the immunity status in the health of organisms. Concerning population preservation, biomarkers relative to reproductive processes are undoubtedly relevant and promising. Regarding field studies, D. polymorpha and G. fossarum could be used not only in passive biomonitoring but also in active strategies. In fact, the caging of individuals from the same population (and a fortiori the same species) in different sites (1) limits or avoids the influence of intrinsic parameters and (2) exposes organisms for a controlled time period, so that recent contamination can be evidenced. As for the contamination level or associated biological effects, several studies have underlined the value of the active biomonitoring approach using $D$. polymorpha [37-39] and the amphipod G. fossarum [40, 41]. Therefore, they constitute valuable bioindicator species, largely used as a freshwater biomonitoring tool [35, 42, 43], as illustrated in the next sections by studies undertaken in the PIREN-Seine programme. 


\subsection{Monitoring of Oxidative Stress in Fish Models}

\subsubsection{Introduction}

In aerobic organisms, the use of molecular oxygen for the metabolism of organic carbon leads to the generation of reactive oxygen species (ROSs) that refer to oxygen free radicals and nonradical reactive species. The deleterious effects of ROSs are prevented by enzymatic or non-enzymatic antioxidant defence mechanisms. However, an excessive generation of ROS can overwhelm the organism's antioxidant capacity, thus inducing oxidative stress, protein and DNA damage, lipid peroxidation and cellular ageing. The exposure to environmental pollutants also induces oxidative stress, through the formation of ROS during xenobiotic metabolism and especially during the hydroxylation phase catalysed by the cytochrome P-450 monooxygenase system [44, 45]. In addition, antioxidant efficiency can also be reduced by micropollutants.

\subsubsection{Field Applications}

A common approach is based on the comparison of oxidative stress levels between fish populations at clean and polluted sites. Here, our aim was to explore the influence of pollutant load on the ROS levels and antioxidant capacity of chubs at an individual level in the Seine River basin. Feral chubs are expected to be exposed to numerous aquatic pollutants, and it was shown that the muscle pollutant load of chubs from the Seine River followed this pattern: phthalate diesters > pyrethroid pesticides $>$ polychlorinated biphenyls $(\mathrm{PCBs})>$ PAHs $>$ organochlorine pesticides $>$ PBDEs [46]. Plasmatic levels of antioxidant efficiency significantly decreased with increasing levels of phthalate metabolites in chub liver [47]. This result corroborates a previous study in Carassius auratus that highlighted an inhibitory effect of phthalates on antioxidant enzyme activity and expression [48]. Similarly, a study in humans has pointed out that phthalate monoester metabolites in urine samples are positively correlated with increased plasmatic markers of oxidative stress [49]. Hence, the biotransformation of these widespread plasticisers may reduce the antioxidant efficiency in wild chub from the Seine River. Thiobarbituric acid reactive substances (TBARS) are good proxies of oxidative damage that are formed as a byproduct of lipid peroxidation [45]. Our results pointed out a significant increase of TBARS with increasing PCB burden in chub muscle [47], as experimentally shown in goodeid fish (Girardinichthys viviparous) exposed to sublethal concentrations of PCBs [50]. Despite bans since 1975 (use in open systems) and 1987 (use in closed systems), PCBs are still of environmental concern, because these historically persistent organic pollutants bioaccumulate over time in fish [23] and are biomagnified across aquatic food webs [24]. 


\subsection{Value of Digestive Activities as Biomarkers in Two Aquatic Invertebrates: Application to the Seine River Basin}

\subsubsection{Introduction}

All of the biochemical and physiological processes involved in the life cycle of organisms are closely related to energy metabolism. The energy contributions of individuals are determined, among other processes, by their ability to transform raw energy ingested in the form of food into assimilable energy in the form of nutrients. This ability depends in particular on digestive enzyme activities, notoriously sensitive to various chemical stressors [51]. Disruption of digestive processes may affect individual energy balance and result in energy allocation disturbances with possible consequences on individual fitness. Moreover, as part of an environmental quality assessment, variations in enzymatic activities are often one of the first responses to stress; they therefore represent useful points to confirm the occurrence of toxic effects before they are perceptible at higher levels of biological organisation. The PIREN-Seine programme provided the opportunity to study the activity of digestive enzymes in two aquatic organisms largely used in ecotoxicology, the zebra mussel (D. polymorpha) and the gammarid (G. fossarum). This work involved both the characterisation of the studied response variability with respect to biotic and abiotic factors and the application of these tools in the Seine River watershed.

\subsubsection{Characterisation of Digestive Enzyme Activities}

The response of biomarkers might be influenced by environmental factors (both biotic and abiotic), potentially confounding factors that may complicate interpretation of the results. It thus appears necessary to determine the sources of variations, the amplitude of the response modulations related to these confounding factors with respect to the contamination factors, and to specify the measurement conditions of these biomarkers.

In the gammarid, previous experiments conducted under controlled conditions made it possible to study the effects of (1) temperature and conductivity; (2) breeding and moulting cycles in the female; and (3) the quantity of available food [52]. The results indicate that conductivity is not a key parameter influencing the digestive enzyme activities during short-term bioassays. Conversely, temperature must be taken into account for reliable data interpretation, especially in environments with temperatures below $12^{\circ} \mathrm{C}$ [52]. In addition, amylase, cellulase and trypsin activities in females decreased significantly during the reproductive cycle, particularly during the amplexus. In contrast, gammarid males retain higher levels of digestive activity during this breeding season and therefore appear to be unaffected by the development cycle. Finally, the application of trophic stress decreases the activity of amylase, which is observed in both females and males [53]. 


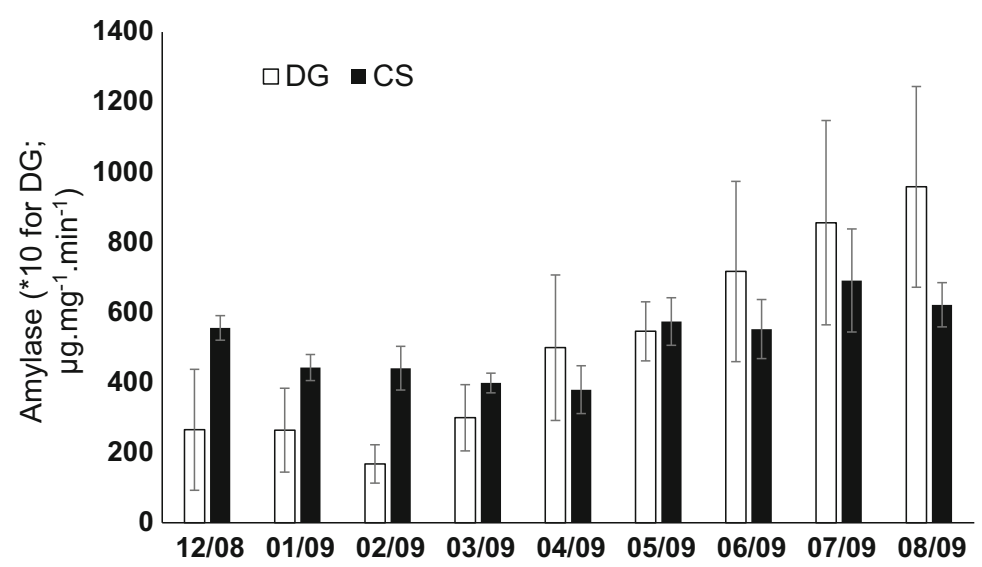

Fig. 2 Seasonal variation in digestive enzyme activities ( $\mu$ g maltose $\mathrm{mg}^{-1}$ protein $\mathrm{min}^{-1}$; mean $\pm \mathrm{SD}, n=7-8$ organs) recorded in the crystalline style (CS) and the digestive gland (DG, concentrations $* 10$ ) of mussels from Vesle over the monitoring period. Monthly sampling dates: i.e. 12/08 corresponds to December 2008; 04/09 corresponds to April 2009

In the case of $D$. polymorpha, a 12-month active biomonitoring study was conducted within the PIREN-Seine programme on the Vesle basin [39]. A clear seasonal trend was observed in the study of the digestive gland (DG), with mussels exhibiting especially high digestive enzyme activities in spring and early summer, competing with the development and maturation of gametes (Fig. 2, illustration for amylase). These digestive patterns were obviously related to the interaction between the reproductive and nutritional status of mussels. It appears that the level of the digestive enzyme activity closely follows temperature variations. While seasonal modulations of amylase and cellulase activities were recorded in the DG of mussels, this was not the case for these activities when recorded in their crystalline style (CS) (Fig. 2, illustration for amylase). The absence of seasonal variations in the CS could be related to the innate nature of the style, i.e. a secretion organ whose weight does not vary according to season. On the contrary, the DG is an organ whose weight exhibits variations over the year, with a potential influence on digestive enzyme activities. When using the DG, the temperature must be taken into consideration during field evaluation [39].

\subsubsection{Consequences of Digestive Activity Impairment}

This aspect was particularly considered in the gammarid G. fossarum. Along with the measurements taken on the activity of digestive enzymes, the energy reserves and responses related to fecundity (number of oocytes) and fertility (number of embryos) in females were quantified in controlled conditions. Concomitantly with the inhibition of the digestive activities studied, a decrease in the available energy (lipids + glycogen + proteins) is observed in females, as well as a decrease in the 
fecundity and fertility of the females subjected to a trophic stress [54]. Thus, the disruption of the digestive capacity of animal organisms could, after 15 days of exposure to trophic stress, induce a risk of reduction of the energy available for reproduction. In the case of exposure to chemical contaminants, in addition to a disruption of the digestive capacity of organisms, it should be noted that individuals must allocate some of their energy to defend mechanisms, potentially to the detriment of reproduction. Therefore, the digestive enzymes studied show their relevance as biomarkers in ecological risk assessment (ERA).

\subsubsection{Field Applications}

Following studies carried out under controlled conditions, a methodology was established for the in situ studies of water quality assessment. The strategy adopted consisted in an active approach to organisms, i.e. transplantation of organisms. Such an approach makes it possible, using calibrated organisms, to limit as much as possible the influence of both endogen (sex, age, etc.) and abiotic (temperature, conductivity, etc.) parameters. To better assess the biological impact of the multicontamination of a small urban river, transplanted zebra mussels were exposed for 2 months at two sites in the Orge River basin, a tributary of the Seine River: one at the outlet of the basin (Athis-Mons, downstream site, highly urbanised) and the other in its upper part (Villeconin, upstream site, rural) [38]. Amylolytic and cellulolytic activities measured in the CS displayed similar response patterns, both activities being always 20-30\% lower downstream than upstream (Fig. 3, illustration for amylase). Two major characteristics of the upstream-downstream gradient may

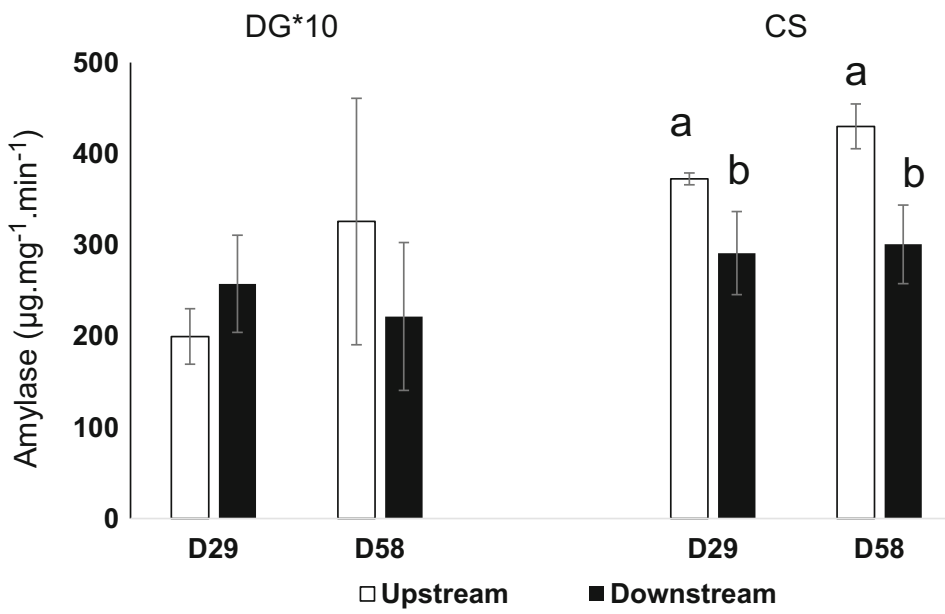

Fig. 3 Amylase activities ( $\mu$ g maltose $\mathrm{mg}^{-1}$ protein $\mathrm{min}^{-1}$ ) measured in digestive gland (DG) and crystalline style (CS) of mussels after 29 days (D29) and 58 days (D58) at both sites (Upstream and Downstream). Different letters upon bars indicate that significant differences were observed (mean $\pm \mathrm{SD}$, $t$-test, $P<0.05$ ) 
explain the differences in CS enzyme activities: the trophic status and the exposure to micropollutants [38]. Contrary to CS, no significant difference between the two sites could be observed for DG enzymes (Fig. 3 illustration for amylase). This contrast between the two organs may be attributed to higher availability of enzymes that may interact with pollutants in extracellular spaces (such as the style sac and stomach lumen) than in intracellular spaces (e.g. the digestive cells of the DG). The water quality along the Seine River (comparison between Marnay-sur-Seine, Bougival and Triel-sur-Seine) also impacted digestive capacity in transplanted gammarids [20]. As with Dreissena, the value of digestive enzymes has also been demonstrated in another model species in ecotoxicology.

\subsubsection{Conclusion}

The objective of the various actions carried out in the PIREN-Seine programme was to validate the use of digestive enzymes in invertebrates as biomarkers of the quality of aquatic environments. The digestive activities were therefore characterised with respect to certain parameters of the environment; their ecological relevance was demonstrated; and, finally, their application in biomonitoring proved to be relevant.

\subsection{Value of Haemocytes of Zebra Mussels for the Development of Immune and Genotoxic Biomarkers}

\subsubsection{Introduction}

Among biomarkers studied in bivalves, those related to the immune system are of great interest since they can be indicative of the health status of an organism. Considered as one of the first lines of defence of the body after the physical barrier of the shell, haemocytes are key cells of individual homeostasis, which can either be activated to counter a chemical or biological stressor or increase their turnover in organisms exposed to contaminated sites to guarantee mussel survival. A functional immune system indicates favourable living conditions for an organism; conversely, a weak immune system could reveal a degraded environment requiring organisms to adapt. For this reason, immune markers are developed to qualify not only the individual's health but also the quality of their environment. With an opened circulatory system, haemolymph circulates through the body, bringing nutrients to the various organs. Drawn from the adductor muscle of bivalves after a small breach in the shell, haemolymph sampling is not lethal for organisms, a clear advantage for biomonitoring studies. Several responses involved in the physiological processes may be measured on haemocytes. For this purpose, a multiple biomarker approach was adopted on haemocytes of $D$. polymorpha, including biomarkers of cytotoxicity (cellular distribution and mortality), genotoxicity (primary DNA strand breaks) and 
immunotoxicity (capacity and efficiency of the phagocytosis process); all of them have shown their relevance in ERA. This strategy has been employed in the PIRENSeine programme to assess the water quality at the three pilot sites along the Seine River following the upstream-downstream gradient: Marnay-sur-Seine, Bougival and Triel-sur-Seine.

\subsubsection{Immune Marker Response}

Two sampling experiments were conducted in different hydrologic conditions: one during the zebra mussel 'breeding' period between May and July 2016 and another one during the 'resting' period between November and December 2016. All mussels originated from the same population in a control site (Sainte Marie du Lac Nuisement, lac du Der-Chantecoq, $\left.48^{\circ} 36^{\prime} 22.02^{\prime \prime} \mathrm{N}, 4^{\circ} 46^{\prime} 34.0^{\prime \prime} \mathrm{E}\right)$. The day after sampling, haemolymph was withdrawn and cellular parameters were measured. Haemocyte distribution, cell mortality and responses relative to the phagocytosis process were measured with flow cytometry. Using this technique, the following data can be acquired: (1) phagocytosis capacity, defined as the percentage of cells which have engulfed at least one bead, quantifies how many haemocytes in the entire cell population are able to ingest beads; (2) phagocytosis efficiency, corresponding to the percentage of cells that have engulfed at least three beads, indicates how much phagocytic cells have efficient phagocytosis activity and are not just randomly bound to beads; and (3) the intensity of phagocytosis activity quantified by the haemocyte avidity, represented by the mean number of beads engulfed per cell. During the first campaign (May-July 2016), the response of haemocyte distribution demonstrated a site effect. In mussels caged at Triel-sur-Seine, $71 \%$ of haemocytes showed an efficient phagocytic activity for both sampling times, whereas it was 10-20\% lower for the two other sites. We did not observe this site effect during the second campaign, but the results were time-dependent. In fact, the mean percentage of phagocytic cells was $79 \%$ in November and 59\% in December. This result was also confirmed by another marker of phagocytic effectiveness: the avidity of haemocytes. In November, the mean avidity of haemocytes was $10 \pm 2$ beads per cell, whereas in December, the average avidity decreased to only $6 \pm 2$ beads per cell. These results would suggest stimulated immune functions in November in comparison with December. Globally, necrosis affected 10-28\% of haemocytes over the year. Thus, the biological endpoints measured with the flow cytometry technique clearly show a site effect on the first campaign with the stimulation of haemocyte functions associated with lower mortality from Marnay-sur-Seine to Triel-sur-Seine. Full interpretation of these results is ongoing. In particular, these results still have to be compared with environmental concentrations of contaminants to confirm their utility as efficient biomarkers in ERA. 


\subsubsection{Genotoxic Marker Response}

In the same field study, primary DNA strand breaks were measured by the comet assay (SCGE, single cell gel electrophoresis assay) in the haemocytes of caged zebra mussels. This assay has gained importance in environmental genotoxicity studies because it is a rapid, relatively inexpensive (compared to other methods) and sensitive technique for highlighting a variety of DNA damage to individual cells, i.e. single-strand breaks (SSBs), double-strand breaks (DSBs) or alkaline-sensitive sites (ALSs) [55]. The results obtained in terms of levels of DNA strand breaks in haemocytes and the sensitivity of zebra mussels to a genotoxic stress were (1) in accordance with immune marker responses (see above) and (2) in keeping with genotoxicity results obtained on other organs (i.e. gills, DG cells) of caged zebra mussels during previous field studies carried out in the PIREN-Seine programme. For example, the upstream-downstream effect related to the gradient of contamination between Marnay-sur-Seine and Triel-sur-Seine was evidenced with the levels of DNA strand breaks in gill cells of zebra mussels. Levels of damage varied according to the duration or the season of transplantation [56]. In the same study, the levels of irreversible chromosomal damage such as micronuclei measured in gills were also positively correlated with PAH bioaccumulation and related to the gradient of water contamination between the three pilot sites. In another study [57], specific DNA adduct patterns with levels varying between 3 and 18 adducts $/ 10^{6}$ nucleotides were detected both in the gills and the DG of mussels, after 1 or 2 months of transplantation at the three sites on the Seine River. Conversely, this was not the case for mussels in the control site. The DNA adduct formation could be correlated with the modulation or the decrease of gene expression implicated in detoxification processes. Further work is necessary to fully understand the relationship between the responses measured at different genomic scales (from DNA to chromosome), as well as the incidence of structural and functional damage (phagocytosis, DNA repair, apoptosis or necrosis, etc.) on cells and, more globally, on individual fitness. Genotoxicity responses may then be regarded not only as biomarkers of exposure but also as biomarkers of effects, which would reinforce their relevance as predictive tools of ecological dysfunctions.

\subsubsection{Conclusion}

In situ experiments demonstrate the relevance of haemocytes as target cells for immune and genotoxic biomarker measurements in D. polymorpha because they reflect the contrasted levels of impact of the sites studied as well as the physiological conditions of mussels in relation to the stage of sexual maturity. Research is continuing for a better characterisation of the seasonal variability of biomarker responses as well as the possible incidence of (a)biotic confounding factors. These aspects are critical to define both thresholds and reference values useful for a robust diagnosis of the environment's quality. Because of their central functions on 
organism physiology, the development of a panel of markers analysed in haemocytes, including cytotoxic, immunotoxic and genotoxic responses and their integration into a 'cellular index', would provide (1) a better understanding of the overall toxicity on the mussel's physiology and (2) new data for integrative tools designed for the diagnosis of environmental quality.

\section{Combining Multidisciplinary Data for a Global Environmental Quality Diagnosis: Development of an Integrated Approach}

\subsection{Introduction}

The large multidisciplinary scientific network involved in the PIREN-Seine programme has been particularly solicited in the field of ecotoxicology for several years. As a matter of example, between 2011 and 2012, a dozen research groups collaborated on a synchronous and integrative multi-marker approach to assess the chemical and ecological/ecotoxicological status of the three pilot sites, situated upstream and downstream of the Paris agglomeration along the Seine River. This 1-year monitoring study generated about 550 variables per site for each of the four sampling periods (corresponding to distinct seasons). These variables characterised in particular (1) the metallic and organic contamination levels in the water column and in the sediment, (2) the bioaccumulation levels of pollutants of concern and (3) the biological responses (biomarkers) in transplanted gammarids, as well as (4) the (eco)toxicity of water and sediment samples using laboratory bioassays.

Embedding such a multidisciplinary data set in a 'Weight of Evidence' (WOE) approach is widely recommended and even required by regulatory authorities for efficient environmental risk assessment (ERA) [3, 58]. The principle of the WOE approach is based on integrating and combining complementary data from different packages, called 'Lines of Evidence' (LOEs), in order to draw an overall conclusion on the ecological status of the aquatic ecosystem considered [59]. The environmental diagnosis thus results from the combination of contamination levels, bioavailability analyses and biological responses in key species or model organisms at different levels of organisation [60,61]. A helpful model converting a conceptual WOE strategy to evaluate sediment hazard into logical flow charts and calculations was proposed by [62], which was adapted to the data set acquired within the PIRENSeine programme [20]. 


\subsection{The WOE Methodology: Towards an Index of Ecological Disturbance}

The WOE methodology consisted in gathering the selected parameters into four LOEs: sediment and water chemistry (contamination level analysis), contaminant bioavailability (bioaccumulation levels in caged gammarids), biomarker responses (in gammarids) and bioassay responses (on sediment and water samples). A hazard quotient (HQ) was then calculated for each LOE and reported in an evaluation grid for a rapid and clear hazard classification (i.e. ranging from absent to severe). An overall risk assessment was finally obtained by compiling the HQs of the four LOEs into a single index (WOE index) associated with a global hazard class. In addition to the quality and the relevance of the data, there are some prerequisites for parameter integration in the model: the availability of a reference value for each endpoint and, for biological endpoints, an additional threshold value defining the basal/natural variations of the response considered is needed. Accordingly, around 160 endpoints acquired between 2011 and 2012 were selected to be injected into the model. They included 27 and 60 substances of concern for the water column and sediment contamination, respectively (LOE chemistry); 37 compounds bioaccumulated in gammarids (LOE bioavailability); 9 biological responses characterising neurotoxicity, energy acquisition, feeding rate, reproduction and survival in caged gammarids (LOE biomarkers); and 11 and 14 endpoints assessing survival, development, teratogenicity, growth, endocrine disruption, cytotoxicity and genotoxicity using bioassays on water and sediment samples, respectively (LOE bioassays) [20]. Data integration was performed for the three sites and the four sampling campaigns, as well as for an annual average for each site. One of the strengths of the model stems from the differential weighting of each endpoint. For instance, each compound integrated into the chemical and the bioavailability LOEs is weighted according to its status in the Water Framework Directive [63], giving higher weighting factors to priority hazardous substances and priority substances. In the biomarker and bioassay LOEs, each endpoint is weighted against the biological significance of the response considered according to an arbitrary scale of 0-3. For bioassays, the weighting factors also take into account the test matrix and the exposure duration [20,62]. Moreover, the procedure was improved (1) using external reference values for biomarkers and bioaccumulation levels established for the same population of gammarids during previous studies and (2) integrating natural variations of the responses as well as the effects of confounding factors.

\subsection{Application of the Integrative WOE Approach to a 1-Year Case Study on the Seine River}

The HQs generated for the annual average clearly reflected the well-known anthropogenic gradient along the Seine River, with the lowest values observed for 

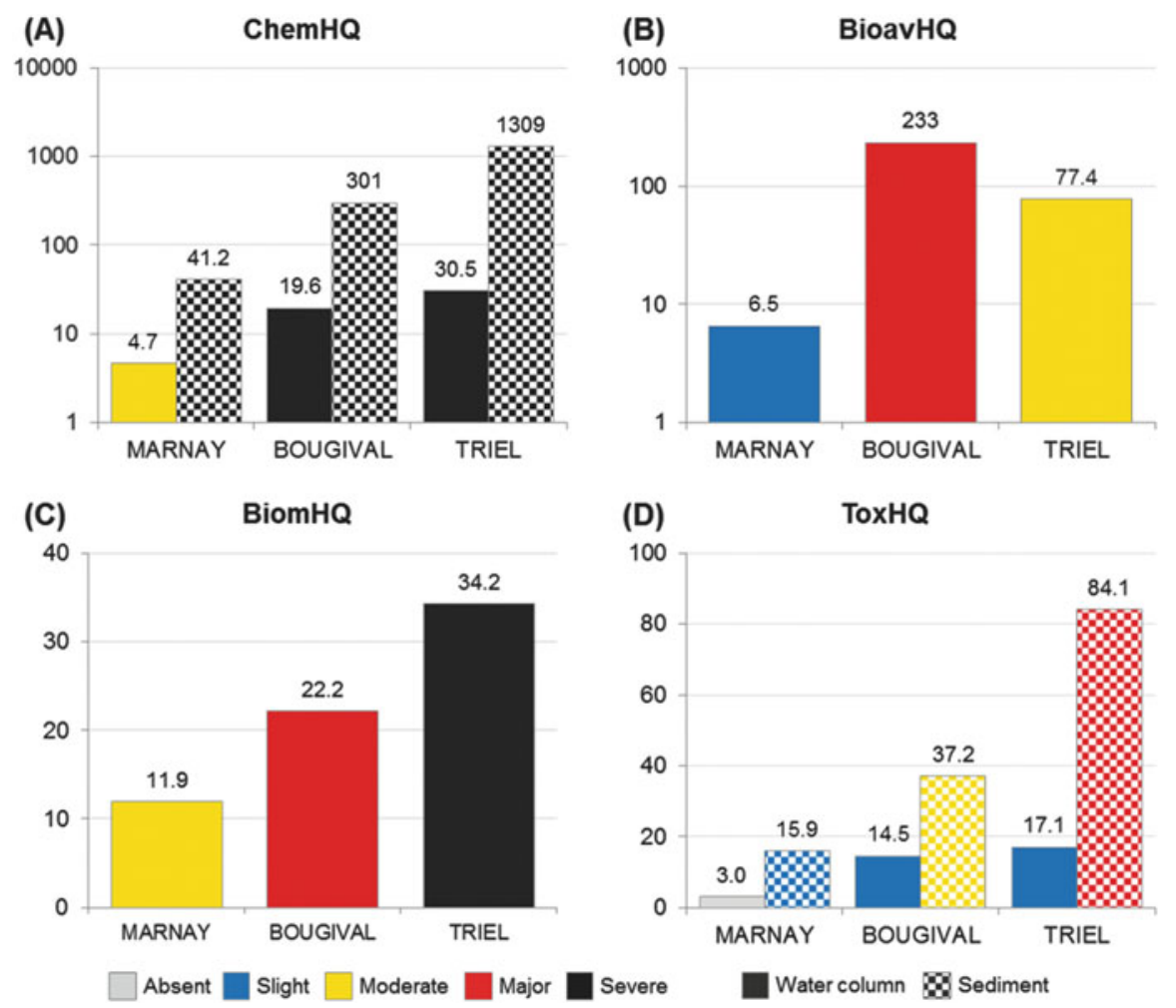

Fig. 4 Annual hazard quotients generated from the LOEs chemistry (a), bioavailability (b), biomarkers (c) and bioassays (d) for the three sites of the Seine River: Marnay-sur-Seine (upstream of Paris), Bougival (about $40 \mathrm{~km}$ downstream of Paris) and Triel-sur-Seine (about $80 \mathrm{~km}$ downstream of Paris and the Oise River confluence). Data taken from [20]

Marnay-sur-Seine (upstream of Paris) and the highest for the two downstream sites (Bougival and Triel-sur-Seine) (Fig. 4). Three out of four LOEs identified Triel-surSeine as the most heavily impacted site. However, the highest HQ value was observed for Bougival within the LOE bioavailability (Fig. 4b). The hazard classification was also widely dependent on the LOE: it varied, for instance, from absent (ToxHQ for water samples; Fig. 4d) to severe (ChemHQ for sediment samples; Fig. 4a) for Marnay-sur-Seine and from slight (ToxHQ for water samples; Fig. 4d) to severe (ChemHQ for water and sediment samples and BiomHQ; Fig. 4a, c) for Trielsur-Seine. The ChemHQs calculated for sediment evaluated as severe the risk associated with the chemical contamination for all sites (Fig. 4a). While the ChemHQ values increased along the downstream-upstream gradient, the hazard classes attributed to each site based on contaminant analysis in sediments failed to discriminate the three stations, contrary to the other LOEs. Conversely, the toxicity testing of water samples did not reveal a significant risk at any of the three sites. This shows that the results, if interpreted independently, can alternatively over- or underestimate the environmental risk depending on the LOE considered. 
(A)

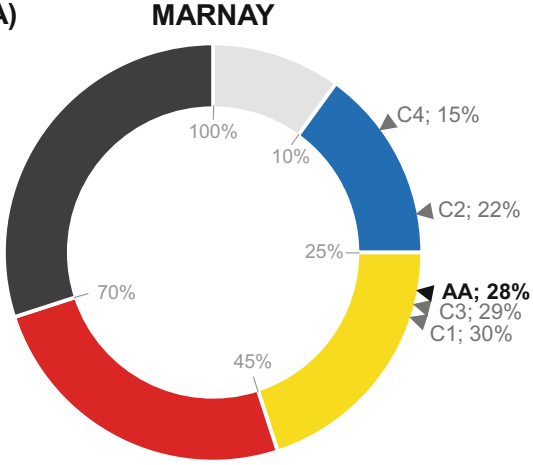

(C)

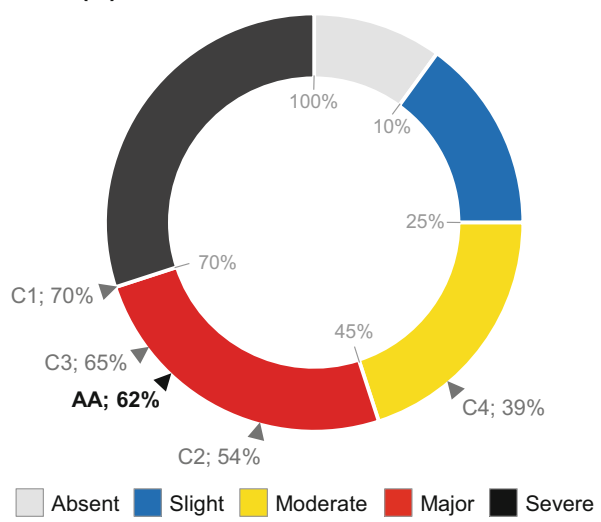

(B) BOUGIVAL

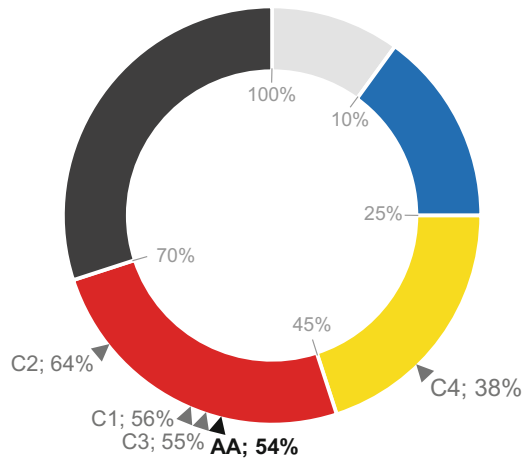

Fig. 5 WOE indexes generated for Marnay-sur-Seine (a), Bougival (b) and Triel-sur-Seine (c) for the four sampling periods (C1-C4) and the annual average (AA). C1, autumn 2011; C2, spring 2012; C3, summer 2012; C4, winter 2012. Note that only data on water contamination and bioavailability were evaluated in the C2 campaign. Data taken from [20]

This again highlights the importance of a multidisciplinary approach to evaluate the global environmental risk in aquatic ecosystems. Indeed, a comprehensive and efficient ERA must jointly evaluate a site's contamination (i.e. level of contaminants in the environment) and pollution status (i.e. including the incidence and the severity of the biological impacts of the contamination) [2, 64].

In this study, the overall risk assessment was reached with the final WOE integration (Fig. 5). Annual WOE indexes reflected the anthropogenic gradient with a moderate hazard in Marnay-sur-Seine and a major hazard for the Bougival and Triel-sur-Seine stations. Seasonal trends were also highlighted with the winter campaign (C4: high-flow period) associated with slight to moderate hazard, whereas the autumn campaign $(\mathrm{C} 1$ : low-flow period) resulted in the highest risk (moderate to major, with the Triel-sur-Seine value very close to the severe hazard class; Fig. 5). These observations are in line with the seasonal flow rate variations in the Seine 
River, generating a dilution or a concentration of the contaminants during the respective sampling periods [65].

The final integration coherently synthesised the outputs of each LOE. Despite its high integrative dimension, this method did not result in a loss of information. The identification of the (class of) contaminants or biological endpoints responsive for the HQ values is possible by calculating endpoint contribution within each LOE. This procedure was able, for instance, to identify perfluorooctanesulfonic acid (PFOS) as an ubiquitous contaminant along the segment of the Seine River studied, with measured concentrations in the water column systematically above the environmental quality standard of $0.65 \mathrm{ng} / \mathrm{L}$. This data examination also pinpointed the herbicide metazachlor as a specific contaminant for the winter period. The contributions calculated within the LOE bioavailability indicated that PAHs were the main problematic class of compounds regarding their bioaccumulation in gammarids at the two downstream stations. In particular, pyrene and fluoranthene exceeded more than 30- and 10-fold the gammarid basal impregnation levels in organisms transplanted in Bougival and Triel-sur-Seine, respectively. Within the LOE biomarker, contribution examinations resulted in differential response spectra depending on the site. For the annual results, only a slight decrease in gammarid survival was responsive for the BiomHQ calculated for Marnay-sur-Seine, whereas in Triel-sur-Seine the response spectrum was more complex with noticeable contributions of reproduction, feeding, energy acquisition and survival markers. In a more general way, contributions of HQ values to the annual WOE indexes were particularly high for the ChemHQs (from 80\% for Marnay-sur-Seine to 54\% for Triel-surSeine), indicating a noticeable contamination of the sites, including the upstream station usually considered as a reference site. These contributions decreased for the downstream sites as the annual ToxHQs and BiomHQs increased their contributions to around $30 \%$ for Bougival and up to more than $40 \%$ at Triel-sur-Seine. This traced the emergence of toxic responses in caged gammarids downstream of Paris in relation to the contamination levels, thus classifying these sites as polluted.

\subsection{Conclusion}

One of the main challenges of the study was to propose a way to compile, synthesise and interpret the countless results of the multi-marker study conducted between 2011 and 2012. The WOE approach developed was successfully applied in this context and resulted in an integrative ERA based on the compilation of more than 150 endpoints to characterise the contamination/pollution status of each site. The results of this method are easily interpreted and transferable to environmental stakeholders through the generation of a global index of perturbation (WOE index) associated with a hazard class. However, several biological responses studied during the programme could not be integrated into the model due to the lack of available references. In particular, modifications of bacterial communities and tolerance acquisition in biofilms (pollution-induced community tolerance 'PICT' method) 
gave results that highly agreed with those generated by the model. Such endpoints are particularly useful in an ERA because they reflect alterations at higher levels of biological organisation (i.e. community level). The development of robust baselines for this type of response would be very valuable for their integration into the WOE approach, widening the type of biological responses included in the model.

The versatility of the WOE model allows its application in a wide variety of contexts. For instance, it can be considered to monitor the environmental repercussions of installations, industries and river development or rehabilitation projects: the model would be helpful to characterise the global ecological impact by comparing the results before and after such modifications of the environment. This tool could also be applicable in the context of temporal and comparative monitoring of study sites, e.g. along the Seine River continuum.

\section{Conclusions and Perspectives}

The different examples given in this chapter illustrate the application of a wide array of bioassays or biomarkers in the PIREN-Seine programme, which aimed to investigate the ecotoxicological quality of the Seine River and some of its tributaries (e.g. Oise and Orge). With the development of new biotechnologies, bioassays and biomarkers will certainly evolve in the future to (1) improve our knowledge of toxic pathways of water contaminants and (2) increase their sensitivity in the detection of adverse effects on biota linked to water contamination. For instance, the recent development of 'omics' appears promising to identify new biological targets of emerging contaminants. In the near future, there is no doubt that the establishment of both reference and threshold values of biomarkers will authorise their integration into ERA for monitoring the efficiency of water treatment plants or restoration schemes for aquatic ecosystems, as may be requested by national or European directives. However, biomonitoring water quality may not be restricted to a limited geographic area and must cover the entire ecological continuum, from continental waters to the estuary as for the Seine River, for example, or must be carried out jointly between European members for cross-border rivers. For this type of biomonitoring survey, we need to go beyond various technical and scientific barriers, implying the choice of several species belonging to the same taxa along the salinity gradient (from continental to brackish/marine waters) representative of aquatic ecosystems and various trophic levels; a single species could not live along the entire continuum. Likewise, the development of reference and threshold values for biomarkers will allow responses between species to be compared. Therefore, the cartography of the overall ecotoxicity representative of the different human pressures on watersheds could be established regardless of the target species. This is an exciting challenge that will guide our research strategies on the Seine River basin for the coming years. 
Acknowledgements This work was conducted in the framework of the PIREN-Seine research programme (www.piren-seine.fr), a component of the Zone Atelier Seine within the international Long Term Socio Ecological Research (LTSER) network.

\section{References}

1. Billen G, Garnier J, Mouchel JM et al (2007) The Seine system: introduction to a multidisciplinary approach of the functioning of a regional river system. Sci Total Environ 375:1-12. https://doi.org/10.1016/j.scitotenv.2006.12.001

2. Chapman PM (2007) Determining when contamination is pollution - weight of evidence de terminations for sediments and effluents. Environ Int 33:492-501

3. European Commission (EC) (2000) Directive 2000/60/EC of the European Parliament and of the Council of 23 October 2000 establishing a framework for Community action in the field of water policy. Off J Eur Union 327:1-73

4. Kabir ER, Rahman MS, Rahman I (2015) A review on endocrine disruptors and their possible impacts on human health. Environ Toxicol Pharmacol 40:241-258

5. Wagner M, Kienle C, Vermeirssen ELM et al (2017) Endocrine disruption and in vitro eco toxicology: recent advances and approaches. Adv Biochem Eng Biotechnol 157:1-58

6. Teil MJ, Tlili K, Blanchard M et al (2014) Polychlorinated biphenyls, polybrominated diphenyl ethers, and phthalates in roach from the Seine River basin (France): impact of densely urbanized areas. Arch Environ Contam Toxicol 66:41-57

7. Sumpter J, Jobling S (1995) Vitellogenesis as a biomarker for estrogenic contamination of the aquatic environment. Environ Health Perspect 103:173-178

8. Tousova Z, Oswald P, Slobodnik J et al (2017) European demonstration program on the effectbased and chemical identification and monitoring of organic pollutants in European surface waters. Sci Total Environ 601-602:1849-1868

9. Leusch FDL, Neale PA, Hebert A et al (2017) Analysis of the sensitivity of in vitro bioassays for androgenic, progestagenic, glucocorticoid, thyroid and estrogenic activity: suitability for drinking and environmental waters. Environ Int 99:120-130

10. Wangmo C, Jarque S, Hilscherová K et al (2018) In vitro assessment of sex steroids and related compounds in water and sediments - a critical review. Environ Sci Process Impacts 20:270-287

11. Jugan ML, Oziol L, Bimbot $M$ et al (2009) In vitro assessment of thyroid and estrogenic endocrine disruptors in wastewater treatment plants, rivers and drinking water supplies in the greater Paris area (France). Sci Total Environ 407:3579-3587

12. Gasperi J, Moreau-Guigon E, Labadie P et al (2011) Contamination de la Seine par les micropolluants organiques: Effet des conditions hydriques et de l'urbanisation. PIREN-Seine, Phase V, Rapport de synthèse 2007-2010

13. Miège $\mathrm{C}$, Karolak $\mathrm{S}$, Gabet $\mathrm{V}$ et al (2009) Evaluation of estrogenic disrupting potency in aquatic environments and urban wastewaters by combining chemical and biological analysis. Trends Anal Chem 28:186-195

14. EFSA (2015) Scientific opinion on the risks to public health related to the presence of bisphenol A (BPA) in foodstuffs: opinion on BPA. EFSA J 13:3978

15. ANSES (2017) Élaboration de VTR par voie orale fondée sur des effets reprotoxiques pour les nonylphénols. Saisine $\mathrm{n}^{\circ}$ 2017-SA-0211

16. Jarošová B, Bláha L, Giesy JP et al (2014) What level of estrogenic activity determined by in vitro assays in municipal waste waters can be considered as safe? Environ Int 64:98-109

17. Fenet H, Gomez E, Pillon A et al (2003) Estrogenic activity in water and sediments of a French river: contribution of alkylphenols. Arch Environ Contam Toxicol 44:1-6 
18. Kinani S, Bouchonnet S, Creusot $\mathrm{N}$ et al (2010) Bioanalytical characterisation of multiple endocrine- and dioxin-like activities in sediments from reference and impacted small rivers. Environ Pollut 158(1):74-83

19. Creusot N, Dévier MH, Budzinski H et al (2016) Evaluation of an extraction method for a mixture of endocrine disrupters in sediment using chemical and in vitro biological analyses. Environ Sci Pollut Res 23(11):10349-10360. https://doi.org/10.1007/s11356-016-6062-1

20. Barjhoux I, Fechner LC, Lebrun JD et al (2018) Application of a multidisciplinary and integrative weight-of-evidence approach to a 1-year monitoring survey of the Seine River. Environ Sci Pollut Res 25:23404-23429. https://doi.org/10.1007/s11356-016-6993-6

21. Brack W, Dulio V, Ågerstrand M et al (2017) Towards the review of the European Union Water Framework management of chemical contamination in European surface water resources. Sci Total Environ 576(2017):720-737

22. Zuykov M, Pelletier E, Harper D (2013) Bivalve mollusks in metal pollution studies: from bioaccumulation to biomonitoring. Chemosphere 93:201-208

23. Vives I, Grimalt JO, Ventura M et al (2005) Age dependence of the accumulation of organochlorine pollutants in brown trout (Salmo trutta) from a remote high mountain lake (Redo, Pyrenees). Environ Pollut 133(2):343-350

24. Kelly BC, Ikonomou MG, Blair JD et al (2007) Food web-specific biomagnification of persistent organic pollutants. Science 317(5835):236-239

25. Rowe CL (2008) The calamity of so long live: life histories, contaminants, and potential emerging threats to long-lived vertebrates. Bioscience 58(7):623-631. https://doi.org/10.1641/ B580709

26. Flammarion P, Devaux A, Nehls S et al (2002) Multibiomarker responses in fish from the Moselle River (France). Ecotoxicol Environ Saf 51(2):145-153

27. Winter MJ, Verweij F, Garofalo E et al (2005) Tissue levels and biomarkers of organic contaminants in feral and caged chub (Leuciscus cephalus) from rivers in the West Midlands, UK. Aquat Toxicol 73:394-405

28. Krča S, Žaja R, Calic V et al (2007) Hepatic biomarker responses to organic contaminants in feral chub (Leuciscus cephalus) - laboratory characterization and field study in the Sava river, Croatia. Environ Toxicol Chem 26:2620-2633

29. Durand JD, Persat H, Bouve Y (1999) Phylogeography and postglacial dispersion of the chub Leuciscus cephalus in Europe. Mol Ecol 8:989-997

30. Devaux A, Flammarion P, Bernardon V et al (1998) Monitoring of the chemical pollution of the River Rhone through measurement of DNA damage and cytochrome P4501A induction in chub (Leuciscus cephalus). Mar Environ Res 46:257-262

31. Larno V, Laroche J, Launey S et al (2001) Responses in chub (Leuciscus cephalus) populations to chemical stress assessed by genetic markers, DNA damage and cytochrome P4501A induction. Ecotoxicology 10:145-158

32. Viganò L, Camoirano A, Izzotti A et al (2002) Mutagenicity of sediments along the Po River and genotoxicity biomarkers in fish from polluted areas. Mutat Res Genet Toxicol 515 (1): $125-134$

33. Binelli A, Della Torre C, Magni S et al (2015) Does zebra mussel (Dreissena polymorpha) represent the freshwater counterpart of Mytilus in ecotoxicological studies? A critical review. Environ Pollut 196:386-403

34. Forrow DM, Maltby L (2000) Toward a mechanistic understanding of contaminant-induced changes in detritus processing in streams: direct and indirect effects on detritivore feeding. Environ Toxicol Chem 19:2100-2106

35. Palos Ladeiro M, Barjhoux I, Bigot-Clivot A et al (2017) Mussel as a tool to define continental watershed. Quality in organismal and molecular malacology. InTech, London. https://doi.org/ 10.5772/67995. Available via https://www.intechopen.com/books/organismal-and-molecularmalacology/mussel-as-a-tool-to-define-continental-watershed-quality 
36. Dedourge-Geffard O, Palais F, Biagianti-Risbourg S, Geffard O, Geffard A (2009) Effects of metals on feeding rate and digestive enzymes in Gammarus fossarum: an in situ experiment. Chemosphere 77:1569-1576

37. Bervoets L, Voets J, Chu S et al (2004) Comparison of accumulation of micropollutants between indigenous and transplanted zebra mussels (Dreissena polymorpha). Environ Toxicol Chem 23(8):1973-1983

38. Bourgeault A, Gourlay-Francé C, Vincent-Hubert F et al (2010) Lessons from a transplantation of zebra mussels in a small urban river: an integrated ecotoxicological assessment. Environ Toxicol 25:468-478

39. Palais F, Dedourge-Geffard O, Beaudon A et al (2012) One-year monitoring of core biomarker and digestive enzyme responses in transplanted zebra mussels (Dreissena polymorpha). Ecotoxicology 21(3):888-905

40. Coulaud R, Geffard O, Xuereb B et al (2011) In situ feeding assay with Gammarus fossarum (Crustacea): modelling the influence of confounding factors to improve water quality biomonitoring. Water Res 45:6417-6429

41. Lacaze E, Devaux A, Mons R et al (2011) DNA damage in caged Gammarus fossarum amphipods: a tool for freshwater genotoxicity assessment. Environ Pollut 159:1682-1691

42. Borcherding $J$ (2010) Steps from ecological and ecotoxicological research to the monitoring for water quality using the zebra mussel in a biological warning system. In: van der Velde G, Rajagopal S, bij de Vaate A (eds) The zebra mussel in Europe. Backhuys Publishers/Margraf Publishers, Leiden/Welkersheim, pp 279-283

43. Voets J, Bervoets L, Smolders R et al (2010) Biomonitoring environmental pollution in freshwater ecosystems using Dreissena polymorpha. In: van der Velde G, Rajagopal S, bij de Vaate A (eds) The zebra mussel in Europe. Backhuys Publishers/Margraf Publishers, Leiden/ Welkersheim, pp 301-321

44. Valavanidis A, Vlahogianni T, Dassenakis M et al (2006) Molecular biomarkers of oxidative stress in aquatic organisms in relation to toxic environmental pollutants. Ecotoxicol Environ Saf 64(2):178-189

45. Lushchak V (2011) Environmentally induced oxidative stress in aquatic animals. Aquat Toxicol 101:13-30

46. Goutte A, Alliot F, Azimi S et al (2018) Influence du niveau trophique sur l'imprégnation des chesvesnes par les micropolluants organiques en agglomération parisienne. Rapport PIRENSeine

47. Goutte A (2018) Métabolisation des micropolluants: Imprégnation et dommages potentiels chez les poissons d'eau douce de la Marne et de ses affluents. Rapport Agence de l'Eau Seine Normandie

48. Qu R, Feng M, Sun P et al (2015) A comparative study on antioxidant status combined with integrated biomarker response in Carassius Auratus fish exposed to nine phthalates. Environ Toxicol 30(10):1125-1134. https://doi.org/10.1002/tox.21985

49. Ferguson KK, McElrath TF, Chen YH et al (2014) Urinary phthalate metabolites and biomarkers of oxidative stress in pregnant women: a repeated measures analysis. Environ Health Perspect 123(3):210-216

50. Vega-López A, Galar-Martínez M, Jiménez-Orozco FA et al (2007) Gender related differences in the oxidative stress response to PCB exposure in an endangered goodeid fish (Girardinichthys viviparus). Comp Biochem Physiol A Mol Integr Physiol 146(4):672-678

51. Dedourge-Geffard O, Palais F, Geffard A et al (2013) Origin of energy metabolism impairments. In: Amiard-Triquet C, Amiard JC, Rainbow PS (eds) Ecological biomarkers - indicators of Ecotoxicological effects. CRC Press, Taylor \& Francis Group, Boca Raton, pp 279-306

52. Charron L, Geffard O, Chaumot A et al (2013) Effect of water quality and confounding factors on digestive enzyme activities in Gammarus fossarum. Environ Sci Pollut Res 20:9044-9056

53. Charron L, Geffard O, Chaumot A et al (2014) Influence of molting and starvation on digestive enzyme activities and energy storage in Gammarus fossarum. PLoS One 9(4):e96393. https:// doi.org/10.1371/journal.pone.0096393 
54. Charron L, Geffard O, Chaumot A et al (2015) Consequences of lower food intake on the digestive enzymes activities, the energy reserves and the reproductive outcome in Gammarus fossarum. PLoS One 10(4):e0125154. https://doi.org/10.1371/journal.pone.0125154

55. de Lapuente J, Lourenço J, Mendo SA et al (2015) The comet assay and its applications in the field of ecotoxicology: a mature tool that continues to expand its perspectives. Front Genet 6:180. https://doi.org/10.3389/fgene.2015.00180

56. Michel C, Bourgeault A, Gourlay-Francé C et al (2013) Seasonal and PAH impact on DNA strand-break levels in gills of transplanted zebra mussels. Ecotoxicol Environ Saf 92:18-26

57. Chatel A, Faucet-Marquis V, Gourlay-Francé C et al (2015) Genotoxicity and activation of cellular defenses in transplanted zebra mussels Dreissena polymorpha along the Seine River. Ecotoxicol Environ Saf 114:241-249

58. US EPA (2016) Weight of evidence in ecological assessment. Epa/100/R-16/001

59. Burton GA, Chapman PM, Smith EP (2002) Weight-of-evidence approaches for assessing ecosystem impairment. Hum Ecol Risk Assess 8:1657-1673. https://doi.org/10.1080/ 20028091057547

60. Chapman PM, Hollert H (2006) Should the sediment quality triad become a tetrad, a pentad, or possibly even a hexad? J Soils Sediments 6:4-8. https://doi.org/10.1065/jss2006.01.152

61. Dagnino A, Sforzini S, Dondero F et al (2008) A "Weight-of-Evidence" approach for the integration of environmental "Triad" data to assess ecological risk and biological vulnerability. Integr Environ Assess Manag 4:314-326. https://doi.org/10.1897/IEAM_2007-067.1

62. Piva F, Ciaprini F, Onorati F et al (2011) Assessing sediment hazard through a weight of evidence approach with bioindicator organisms: a practical model to elaborate data from sediment chemistry, bioavailability, biomarkers and ecotoxicological bioassays. Chemosphere 83:475-485. https://doi.org/10.1016/j.chemosphere.2010.12.064

63. European Commission (EC) (2013) Directive 2013/39/EU of the European Parliament and of the Council of 12 August 2013 amending Directives 2000/60/EC and 2008/105/EC as regards priority substances in the field of water policy

64. Chapman PM, Wang F, Janssen CR et al (2003) Conducting ecological risk assessments of inorganic metals and metalloids: current status. Hum Ecol Risk Assess 9:641-697

65. Labadie P, Munoz G, Peluhet L et al (2013) Les polluants organiques persistants dans la Seine: dynamique spatio-temporelle et transfert vers le compartiment biologique, Rapport d'activité PIREN-Seine

Open Access This chapter is licensed under the terms of the Creative Commons Attribution 4.0 International License (http://creativecommons.org/licenses/by/4.0/), which permits use, sharing, adaptation, distribution and reproduction in any medium or format, as long as you give appropriate credit to the original author(s) and the source, provide a link to the Creative Commons licence and indicate if changes were made.

The images or other third party material in this chapter are included in the chapter's Creative Commons licence, unless indicated otherwise in a credit line to the material. If material is not included in the chapter's Creative Commons licence and your intended use is not permitted by statutory regulation or exceeds the permitted use, you will need to obtain permission directly from the copyright holder.

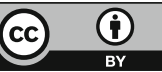

